\title{
Effect of Preparing Conditions on the Phase Constitution and Magnetic Properties of $\mathrm{Nd}-\mathrm{Pr}-\mathrm{Fe}-\mathrm{Zr}-\mathrm{B}$ Alloy Ribbons
}

\author{
A. Ceglarek, P. Gębara* and D. PŁusa \\ Institute of Physics, Częstochowa University of Technology, al. Armii Krajowej 19, 42-200 Częstochowa, Poland

\begin{abstract}
The aim of presented work was to study influence of preparing conditions on phase constitution and magnetic properties of the RE-Fe-B nanocomposite magnets doped with Zr. X-ray studies carried out for samples obtained under lower pressure of Ar atmosphere $\left(0.6 \times 10^{5} \mathrm{~Pa}\right)$ revealed higher ability to formation of nanocrystalline structure. In case of higher pressure of $\mathrm{Ar}\left(0.8 \times 10^{5} \mathrm{~Pa}\right)$ it was possible to obtain full amorphous ribbon during melt-spinning process. The best magnetic properties (means the higher values of coercivity field ${ }_{J} H_{\mathrm{c}}$, remanence $J_{\mathrm{r}}$ and maximum energy product $\left.(B H)_{\max }\right)_{5}$ were measured for sample prepared with the lowest copper wheel speed $20 \mathrm{~m} / \mathrm{s}$ and higher pressure of $\operatorname{Ar}\left(0.8 \times 10^{5} \mathrm{~Pa}\right)$.
\end{abstract}

DOI: 10.12693/APhysPolA.127.570

PACS: 75.30.Et, 91.60.Pn

\section{Introduction}

Nanocomposite magnets consisting of two phases i.e. magnetically soft $\alpha$-Fe and magnetically hard $\mathrm{RE}_{2} \mathrm{Fe}_{14} \mathrm{~B}$ $(\mathrm{RE}=\mathrm{Nd}, \mathrm{Pr}$, Dy) belong to the latest generation of permanent magnets. Although many experimental and theoretical papers have been published so far their properties are still intensively investigated. Magnetic parameters such as: coercivity ${ }_{J} H_{\mathrm{c}}$, remanence polarization $J_{\mathrm{r}}$, saturation polarization $J_{\mathrm{s}}$, and maximum energy product $(B H)_{\max }$ depend not only on the phase composition but also on their microstructure, determined by the method of production. Magnets with the content of rare earth elements lower than stoichiometric composition of $\mathrm{RE}_{2} \mathrm{Fe}_{14} \mathrm{~B}$ phase $(\mathrm{RE}<11.7$ at.\%) and the grain size lower than $45 \mathrm{~nm}$ exhibit enhanced remanence and maximum energy product [1-3]. The remanence enhancement is attributed to the exchange interactions between nanometric grains of magnetically soft and hard phases [4]. The remanence polarization to the saturation polarization ratio $J_{\mathrm{r}} / J_{\mathrm{s}}$, which is larger than $0.5\left(J_{\mathrm{r}} / J_{\mathrm{s}}=0.5\right.$ according to the Stoner-Wohlfarth theory for single domain noninteracting particles [5]) may be a measure of those interactions. But the exchange interactions lead to the decrease in coercivity. The lower value of coercivity in nanocomposite magnets may be compensated by partly substituting praseodymium for neodymium atoms due to the higher anisotropy field of $\operatorname{Pr}_{2} \mathrm{Fe}_{14} \mathrm{~B}$ phase. As it can be found in literature the best magnetic properties (the highest remanence and maximum energy product) may be obtained for $\mathrm{Nd} / \mathrm{Pr}=1 / 3[3,6]$. Small additions of $\mathrm{Zr}$ or $\mathrm{Nb}$ inhibit the grain growth in the nanocomposite magnets during the microstructure optimizing processes $[7,8]$.

The most common method of producing the magnetic nanocomposite materials is the rapid quenching of the

\footnotetext{
*corresponding author; e-mail: pgebara@wip.pcz.pl
}

liquid alloy on the rotating copper wheel. By choosing the technical parameters properly (parameters such as: pressure of argon in the chamber or linear velocity of the copper wheel). While the influence of the linear velocity of the wheel on the magnetic properties of the ribbon was investigated in many papers [9-12] only one paper was published on the influence of the argon pressure [13].

The aim of this paper was to investigate the phase composition and magnetic properties of the nanocomposite $\left(\mathrm{Nd}_{0.75} \mathrm{Pr}_{0.25}\right)_{10} \mathrm{Fe}_{82} \mathrm{Zr}_{2} \mathrm{~B}_{6}$ ribbons in as-cast state manufactured for different values of Ar pressure in the chamber and for different linear velocities of the copper wheel.

\section{Sample preparation and experimental method}

The base material for producing the ribbons was the $\left(\mathrm{Nd}_{0.75} \mathrm{Pr}_{0.25}\right)_{10} \mathrm{Fe}_{82} \mathrm{Zr}_{2} \mathrm{~B}_{6}$ alloy obtained by arc melting method in protective argon atmosphere. In order to homogenize the material the samples were remelted several times. Nanocomposite and amorphous ribbons were prepared by melt-spinning technique under different parameters, such as the pressure of argon in the chamber and the linear wheel velocity. The pressure was equal to $0.8 \times 10^{5} \mathrm{~Pa}$ and $0.6 \times 10^{5} \mathrm{~Pa}$ and the linear velocity of the wheel was 20,35 , and $45 \mathrm{~m} / \mathrm{s}$.

The phase composition of the ribbons was investigated using the Bruker D8 Advance X-ray diffractometer with $\mathrm{Cu} K_{\alpha}$ radiation and the LynxEye semiconductor detector.

Hysteresis loops of the ribbons were measured using LakeShore vibrating sample magnetometer working at the magnetic field up to $2 \mathrm{~T}$ at the room temperature. From these loops the basic parameters such as remanence polarization, coercivity, and saturation polarization were determined.

The broadening of the diffraction peaks allowed to determine the average grain size for the $\alpha-\mathrm{Fe}$ and $\mathrm{RE}_{2} \mathrm{Fe}_{14} \mathrm{~B}$ phases using Scherrer's method. 


\section{Results and discussion}

Figure 1a,b shows X-ray patterns of the ribbons produced at the pressure equal to $0.6 \times 10^{5} \mathrm{~Pa}, 0.8 \times 10^{5} \mathrm{~Pa}$ and wheel velocity values of $20,35,45 \mathrm{~m} / \mathrm{s}$ in as-cast state. The X-ray patterns for the sample obtained at the larger pressure of argon $\left(0.8 \times 10^{5} \mathrm{~Pa}\right)$ in the chamber possess a broad amorphous halo with clear diffraction peaks related to $\alpha$-Fe and $\mathrm{RE}_{2} \mathrm{Fe}_{14} \mathrm{~B}$ phases. This certifies that the ribbons are partially crystalline. Lowering of the linear velocity causes no decrease in the amorphous halo but increase in the intensity of the diffraction peaks originating from magnetically $\mathrm{RE}_{2} \mathrm{Fe}_{14} \mathrm{~B}$ hard and $\alpha$-Fe soft phases. Figure $1 \mathrm{~b}$ presents $\mathrm{X}$-ray patterns for ribbons produced at lower argon pressure. The X-ray pattern for the ribbon obtained at the largest linear velocity $(45 \mathrm{~m} / \mathrm{s})$ does not exhibit the visible peaks originating from the crystalline phases. This allows to conclude that the ribbon is amorphous. At the lower linear velocity (i.e. $35 \mathrm{~m} / \mathrm{s}$ ) the ribbon obtained has a broad amorphous halo with visible peak for $2 \theta=44.92^{\circ}$ which corresponds to the $\alpha$-Fe phase. Diffraction peaks corresponding to the magnetically soft $\alpha$-Fe and magnetically hard $\mathrm{RE}_{2} \mathrm{Fe}_{14} \mathrm{~B}$ phases for ribbon obtained at the velocity of $20 \mathrm{~m} / \mathrm{s}$ indicate the crystallization of the ribbon.

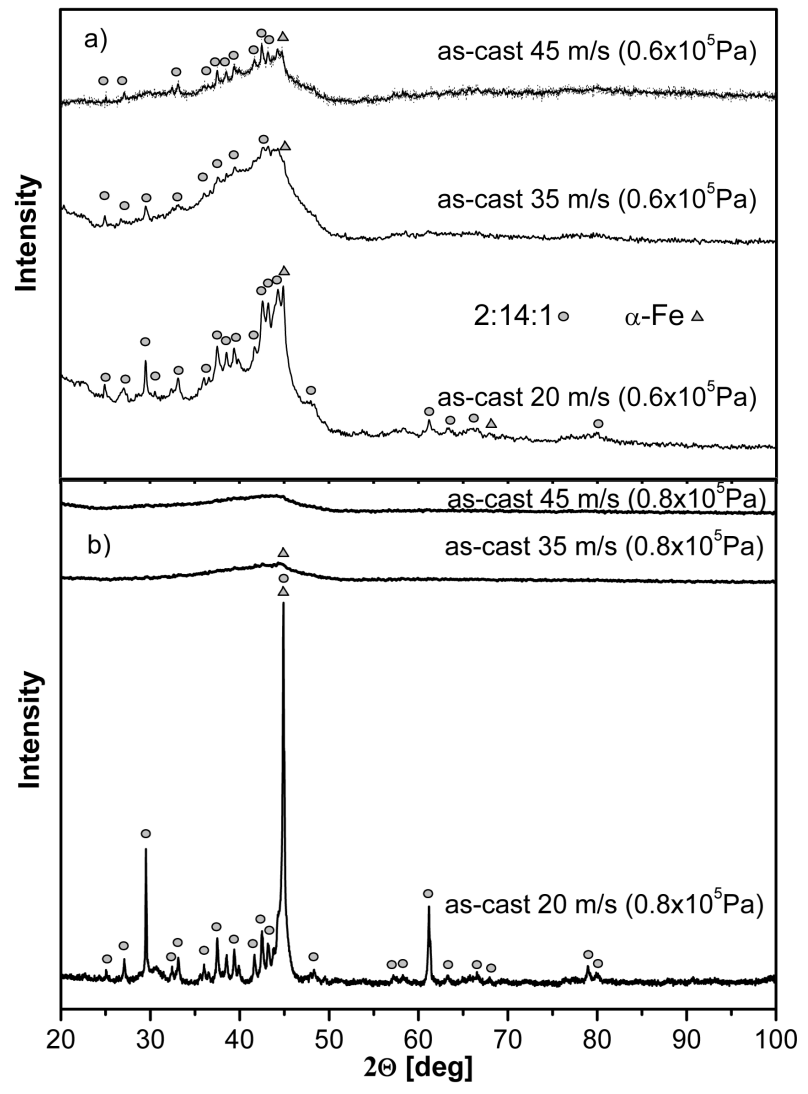

Fig. 1. X-ray diffraction pattern of $\left(\mathrm{Nd}_{0.75} \mathrm{Pr}_{0.25}\right)_{10} \mathrm{Fe}_{82} \mathrm{Zr}_{2} \mathrm{~B}_{6}$ ribbons in as-cast state produced at the pressure (a) $p=0.6 \times 10^{5} \mathrm{~Pa}$ and (b) $p=0.8 \times 10^{5} \mathrm{~Pa}$.
Average grain size estimated using Scherrer's method for the sample produced at the pressure of $0.8 \times 10^{5} \mathrm{~Pa}$ and velocity of $20 \mathrm{~m} / \mathrm{s}$ are $9 \mathrm{~nm}$ for $\alpha$-Fe and $15 \mathrm{~nm}$ for $\mathrm{RE}_{2} \mathrm{Fe}_{14} \mathrm{~B}$, respectively.

Figure 2a shows the magnetic hysteresis loops for ribbons produced at the pressure of $0.6 \times 10^{5} \mathrm{~Pa}$. Demagnetization curve for the ribbon manufactured at the velocity of $20 \mathrm{~m} / \mathrm{s}$ is characteristic for the material consisting of magnetically soft and hard phases which demagnetize independently.

The hysteresis loops for the ribbons produced at the velocities of $35 \mathrm{~m} / \mathrm{s}$ and $45 \mathrm{~m} / \mathrm{s}$ are characteristic for the partially crystallized materials containing the "frozen" nuclei of the future crystalline phases. In Fig. $2 \mathrm{~b}$ the hysteresis loop is shown for the ribbon produced at the pressure of $0.8 \times 10^{5} \mathrm{~Pa}$. For ribbon obtained at the wheel velocity of $20 \mathrm{~m} / \mathrm{s}$ the hysteresis loop is smooth and shows the single-phase behaviour. The ratio $J_{\mathrm{r}} / J_{\mathrm{s}}=0.7$ indicates the existence of strong exchange interactions between magnetically hard and soft phases. The initial magnetization curve for this sample is typical for materials for which the main magnetization reversal mechanism is a pinning of domain walls. The hysteresis loops for the sample produced at the velocity of $35 \mathrm{~m} / \mathrm{s}$ is characteristic for partially crystallized materials. At the largest linear velocity i.e. $45 \mathrm{~m} / \mathrm{s}$ the amorphous ribbon was produced.

The basic magnetic parameters determined from the hysteresis loops are summarized in Table.The sample pro-

TABLE

Coercivity ${ }_{J} \mathrm{H}_{\mathrm{c}}$, remanence polarization $J_{\mathrm{r}}$, saturation polarization $J_{\mathrm{s}}$, maximum energy product $(B H)_{\max }$ and the remanence-to-saturation ratio $J_{\mathrm{r}} / J_{\mathrm{s}}$ depending on the pressure $p$ and linear wheel velocity $v$.

\begin{tabular}{c|c|c|c|c|c|c}
\hline \hline $\begin{array}{c}p \\
{\left[10^{5} \mathrm{~Pa}\right]}\end{array}$ & $\begin{array}{c}v \\
{[\mathrm{~m} / \mathrm{s}]}\end{array}$ & ${ }_{J} H_{\mathrm{c}}[\mathrm{T}]$ & $\begin{array}{c}J_{\mathrm{r}} \\
{[\mathrm{T}]}\end{array}$ & $\begin{array}{c}J_{\mathrm{s}} \\
{[\mathrm{T}]}\end{array}$ & $\begin{array}{c}(B H)_{\max } \\
{\left[\mathrm{kJ} / \mathrm{m}^{3}\right]}\end{array}$ & $J_{\mathrm{r}} / J_{\mathrm{s}}$ \\
\hline \multirow{3}{*}{0.8} & 20 & 0.88 & 0.92 & 1.17 & 136 & 0.79 \\
& 35 & 0.01 & 0.25 & 1.25 & - & - \\
& 45 & \multicolumn{6}{|c|}{ amorphous } \\
\hline \multirow{3}{*}{0.6} & 20 & 0.62 & 1.15 & 1.60 & 52 & 0.72 \\
& 35 & 0.03 & 0.54 & 1.28 & - & - \\
& 45 & - & - & 1.41 & - & -
\end{tabular}

duced at the pressure of $0.8 \times 10^{5} \mathrm{~Pa}$ and the velocity of $20 \mathrm{~m} / \mathrm{s}$ exhibits the largest $B H$ product.

\section{Conclusions}

In present paper the influence of preparing conditions on phase constitution and magnetic properties was investigated. The samples obtained under lower pressure of Ar atmosphere were characterized by higher ability to formation of nanocrystalline structure based on coexistence of soft magnetic $\alpha$-Fe and hard magnetic $\mathrm{RE}_{2} \mathrm{Fe}_{14} \mathrm{~B}$ phases. In the case of higher pressure of Ar, amorphous structure of samples was possible to obtain for the highest velocity of copper wheel during melt-spinning process. 
The best magnetic properties were measured for sample obtained for higher pressure of Ar and the lowest velocity of copper wheel. The shape of hysteresis loop collected for this sample was typical for hard magnetic materials. The remanence to saturation ratio $J_{\mathrm{r}} / J_{\mathrm{s}}=0.7$ certifies that the strong exchange interaction occurs between the hard and soft magnetic grains. The main mechanism of the magnetization reversal process is the pinning of domain walls.

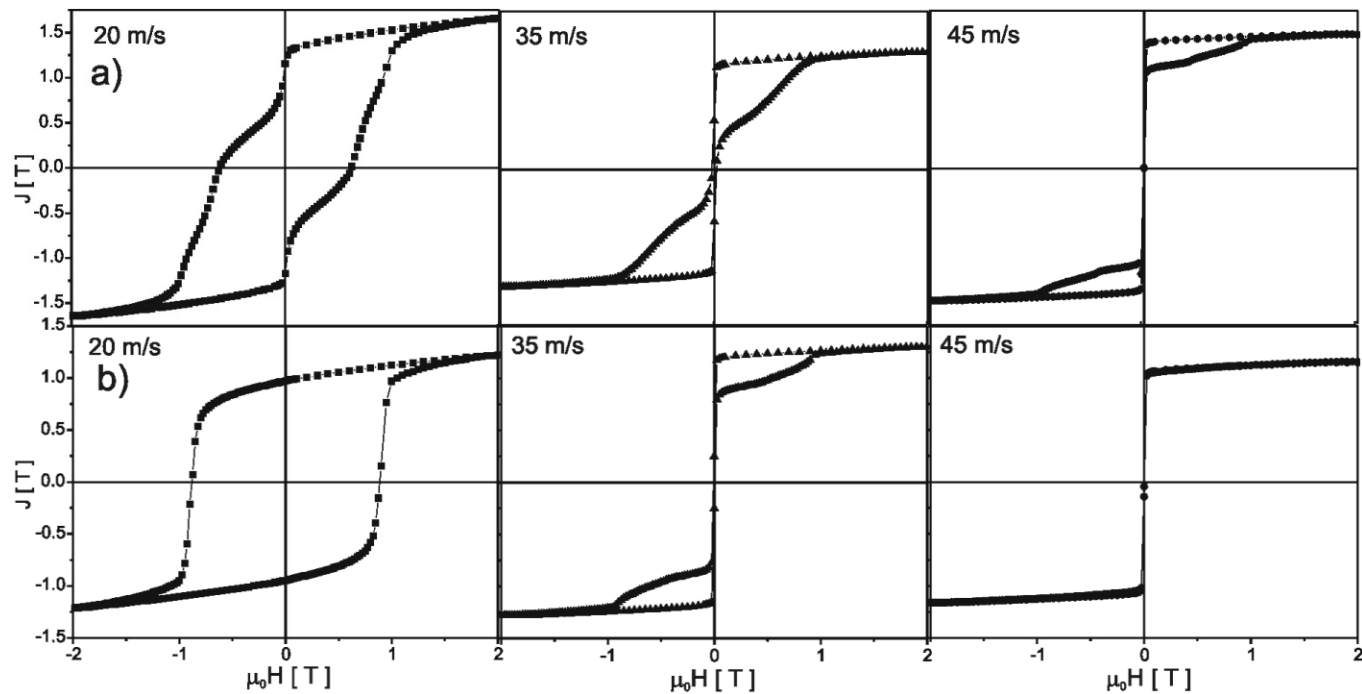

Fig. 2. Hysteresis loops of $\left(\mathrm{Nd}_{0.75} \mathrm{Pr}_{0.25}\right)_{10} \mathrm{Fe}_{82} \mathrm{Zr}_{2} \mathrm{~B}_{6}$ ribbons produced at the pressure (a) $p=0.6 \times 10^{5} \mathrm{~Pa}$ and (b) $p=0.8 \times 10^{5} \mathrm{~Pa}$.

\section{References}

[1] A. Manaf, R.A. Buckley, H.A. Davies, M. Leonowicz, J. Magn. Magn. Mater. 101, 360 (1991).

[2] A. Manaf, R.A. Buckley, H.A. Davies, J. Magn. Magn. Mater. 128, 302 (1993).

[3] H.A. Davies, J.I. Betancourt, C.L. Harland, Scr. Mater. 44, 1337 (2001).

[4] E.F. Kneller, R. Hawig, IEEE Trans. Magn. 27, 3588 (1991).

[5] E.C. Stoner, W.P. Wohlfarth, Philos. Trans. R. Soc. Lond. A 240, 599 (1948).

[6] J.I. Betancourt, H.A. Davies, J. Appl. Phys. 85, 5911 (1999).

[7] J.I. Betancourt, H.A. Davies, J. Magn. Magn. Mater. 261, 328 (2003).
[8] B. Xiaoqian, Z. Jie, L. Wei, G. Xuexu, Z. Shouzeng, J. Rare Earths 27, 843 (2009).

[9] S. Yang, X.S. Liu, S.D. Li, G.Z. Xie, X.P. Song, B.X. Gu, Y.W. Du, Mater. Sci. Eng. A 347, 325 (2003).

[10] G. Mendoza-Suarez, J.I. Escalante-Garcia, J. LopezCuevas, G. Vargas-Gutierrez, H. Mancha-Molinar, J. Mendez-Nonell, J. Magn. Magn. Mater. 206, 37 (1999).

[11] Z. Chen, Y. Zhang, G.C. Hadjipanayis, Q. Chen, B. Ma, J. Magn. Magn. Mater. 206, 8 (1999).

[12] Y. Sen, L. Shandong, L. Xiansong, S. Xiaoping, G. Benxi, D. Youwei, J. Alloys Comp. 343, 217 (2002).

[13] C. Wang, M. Yan, Mater. Sci. Eng. B 128, 216 (2006). 